\title{
What Physical Activities Can Help You Feel Better?: Analysis Based on the 2016 Korean National Health and Nutrition Examination Survey
}

\author{
Seo Hee Park, MD, Young Myo Jae, MD, PhD, Sae Heon Jang, MD, Jin-Hyuk Choi, MD, \\ Gyeong Hwan Lee, MD \\ Department of Psychiatry, Bongseng Memorial Hospital, Busan, Korea
}

\begin{abstract}
Background: This study aimed to investigate the relationship between exercise and depression based on responses to 2016 Korean National Health and Nutrition Examination Survey (KNHANES) and the Patient Health Questionairre-9 (PHQ-9). Specifically, this study examined which physical activities have the greatest effects in combating depression.

Methods: This study was based on data from 2016 KNHANES and responses to the PHQ-9 questionnaire on physical activity. We selected 2,245 people of age $>19$ years, who completed the surveys. Physical activity variables included number of days of walking, duration of walking, days of strength training, and aerobic physical activity. These variables subdivided into aerobic and muscle strengthening activities and their effects on depression were examined.

Results: All the variables, except duration of walking, were negatively correlated with the PHQ- 9 scale scores. However, of the physical activity variables included in the hierarchical regression analysis, only the number of days of walking over 1 week had a statistically significant negative effect on the PHQ-9 scores.

Conclusion: For adults, aerobic activity (walking) had a greater effect on reducing depression than muscle strengthening activity. The frequency and consistency of walking had a greater impact than the duration of walks. These results suggest that regular walking is a better form of physical activity than strength training for its effect on mood and it assists in overcoming depression.
\end{abstract}

Keywords Depression; Walking; Strength training

\section{INTRODUCTION}

Depression goes beyond manifesting negative emotions, but also seriously impairs normal function and daily activities. Depression is more of a problem than just experiencing negative emotions, bringing about substantial functional and daily impairment of the individual and a significant proportion of the leading causes of the increasing suicide rate $[1,2]$.

According to a 2017 survey by the Korean National Statistical Office, suicide is the fifth cause of death among all Koreans, and the most common cause of suicide is depression. Thus, the treatment and prevention of depression is becoming more imperative [3].

Because of the importance of the prevention and treatment of depression, many studies have been conducted. Among them, there are studies on if physical activity is effective in the prevention and treatment of depression $[4,5]$. Physical activity refers to all the movements of the body through energy consumption of skeletal muscle, and regular physical activity has a positive effect on mental health as well as improving physical health, and

Received February 5, 2020, Revised February 12, 2020, Accepted February 18, 2020

Correspondence: Young Myo Jae, MD, PhD

Department of Psychiatry, Bongseng Memorial Hospital, 401 Jungang-daero, Dong-gu, Busan, Korea

TEL +82-51-664-4121 FAX +82-51-631-8054 E-mail ymjae@naver.com ORCID https://orcid.org/0000-0003-4557-0827

Copyright $@$ by Korean Society for Affective Disorders. All Rights reserved.

This is an Open Access article distributed under the terms of the Creative Commons Attribution Non-Commercial License (http://creativecommons.org/licenses/ by-nc/4.0/) which permits unrestricted non-commercial use, distribution, and reproduction in any medium, provided the original work is properly cited. 
preventing chronic diseases [6-9].

More specifically, there is a significant correlation between depression and physical activity such as walking, muscle-strengthening, and aerobic exercise, and exercising regularly is more effective in reducing depression. Corbin et al. [8] found that regular and proper aerobic exercise facilitates improvement of depression. Kim and Suh [10] reported that employees who participated in exercise more than one hour daily had lower depressive symptoms than employees who did not exercise. Additionally, Kim et al. [11] reported that the decrease in muscle mass and strength is a risk factor for depression.

The World Health Organization [12], the United States, Australia, Canada, and many other countries have announced guidelines for physical activity and recommended a level of physical activity to promote health [13-15]. Korea's Ministry of Health and Welfare established the 'Physical Activity Guidelines for Koreans' in 2013. This Korean guideline suggests physical activity by life cycle, classified into children and adolescents, young adults, and adults older than age 65. Although there are some differences in recommendations for physical activity across the life cycles, aerobic physical activity (APA) and muscle-strengthening activity (MSA) are commonly recommended. APA guidelines for adults recommend moderate intense activity (3.0-5.9 times higher than resting) for more than two hours 30 minutes weekly, or vigorous intensity activity (more than 6.0 times higher than resting) for at least one hour 15 minutes weekly, and at least two days weekly for MSA [16].

However, data released by the Korea Centers for Disease Control and Prevention (2014) showed that the APA (vigorous or moderate intensity) of the Korean people decreased $41.5 \%$ in 2008 to $30.6 \%$ in 2012, and there the ratio of complying with APA and MSA guidelines decreased slightly $12.4 \%$ in 2008 to $11.8 \%$ in 2012 [17]. In the United States, conversely, the compliance rate for APA guidelines in 2012 was $49.5 \%$ and that for APA and MSA guidelines was $20.2 \%$. This shows that Korea has lower compliance with physical activity guidelines in APA and MSA than the United States [18].

Although we know that physical activity helps to improve depressive symptoms, it is not easy for people to do physical activity. Thus, it is desirable to assess the degree of physical activity and depression and to examine their associations with health and nutrition examination data recently surveyed in Korea. This can be a good resource for developing and encouraging future physical activity guidelines in Korea.

Several studies on the correlation between APA, such as walking, MSA and depression, exist. However, most of these previous studies were limited to the elderly or middle-age women $[19,20]$, and APA and MSA were treated as the same physical activity without distinction $[9,21,22]$. Few studies have the differeces between the two types of physical activity in Korean adults.

In this study, we classified physical activity into APA and MSA and further sub-classified APA into qualitative (i.e., regularity) or quantitative (i.e., amount) component to determine how it is related to depressive symptom.

\section{MATERIALS AND METHODS}

This study was conducted based on the Korean National Health and Nutrition Examination Survey (KNHANES). And, this study used raw data from the seventh year of the KNHANES conducted in 2016.

The KNHANES is a statutory investigation conducted under the National Health Promotion Act. This is a survey on the health behavior, chronic disease prevalence, food and nutrition intake of the public, and was conducted every three years from the first (1998) to the third (2005). It is held yearly from the beginning of 2007 2009. Since then, it has been reorganized into an annual survey system and has been conducted yearly since the fourth period (2007-2009).

KNHANES was conducted with the approval of the Institutional Review Board of the Korea Centers for Disease Control and Prevention (KCDC). The results of the survey are published through the distribution of press releases, publication of statistics, and the release of raw data until December of the following year. And the KCDC provide only data that has been de-identified so that no individual can be estimated. In 2016, 10,806 were surveyed, of which 8,150 were participants and the participation rate was $75.4 \%$.

The raw data consists of three types: health survey, examination, and nutrition survey. In this study, the results of the health survey were used, conducted through interviews and self-reported surveys. This study was conducted after obtaining the approval of the Institutional Review Board of Bongsaeng Memorial Hospital in Busan, South Korea (No. 2020-002). 


\section{Subjects}

The subjects of this study were older than age 19 and responded to the days of weekly walking exercise (DWWE), the total time of weekly walking exercise (TTWWE), the days of weekly muscle-strengthening exercise (DWMSE), the recommended aerobic physical activity execution status (RAPAES) and Patient Health Questionnaire-9 (PHQ-9). In the case of not responding to any item or responding 'no idea' to the PHQ-9 questionnaire, the subject was excluded. The total number of subjects was 2,245 .

\section{Measurements}

\section{1) Depression (PHQ-9)}

In this study, the Korean standardized PHQ-9 was used to measure the degree of depression.

The PHQ-9 is a nine-item depression screening tool based on the Diagnostic and Statistical Manual of Mental Disorders, 4th Edition. It has better sensitivity (88\%) and specificity (88\%) than the Self-Rating Depression Scale and the Beck Depression Inventory, the two most commonly used current depression measures. And it is a reliable and valid tool for measuring depression severity [23].

According to the existing domestic research, the cutoff value can be set to 9, but the total score of PHQ-9 was considered as the primary measure to use the continuous variable value of the raw data [24].

\section{2) Physical activity}

Using the data of KNHANES, DWWE (unit: days), TTWWE (unit: hours), and DWMSE (unit: days) were used as continuous variables. RAPAES is 'yes' or 'no' and were used as qualitative variables. Then we examined the association between them and the PHQ-9 score and the strength of the association.

\section{3) Covariates (demographic variables)}

Demographic characteristics included sex, age, income, education, marital status, job status, drinking, current smoking status, and body mass index (BMI). Ages were classified into under $30 \mathrm{~s}, 30 \mathrm{~s}, 40 \mathrm{~s}, 50 \mathrm{~s}, 60 \mathrm{~s}$, $70 \mathrm{~s}$, and $80 \mathrm{~s}$ and above. Income levels were classified into lower, low-middle, upper-middle, and upper class according to the income quartile classification. The education level was classified into elementary school, middle school, high school, and college.

Marital and job status were classified into two groups based on the current status. The current smoking group was classified into the smoking group, and the non-smoking group. The BMI was classified into underweight $(<20)$, normal $(20 \leq \mathrm{BMI}<25)$, mild obesity $(25 \leq \mathrm{BMI}<30)$, and obesity $(\mathrm{BMI} \geq 30)$.

\section{Statistical analyses}

Discrete variables such as sex and disease status, were evaluated using the Chi-square test. Since the PHQ9 score was taken as a continuous variable, covariance analysis was used to correct the confounding variable. Pearson's correlation analysis was used to correlate the variables. And hierarchical regression analysis was performed to investigate the variables affecting PHQ9. Statistical significance of this study was defined as pvalue $<0.05$ in both directions, and all statistical analyzes were performed using IBM SPSS Statistics for Windows, Version 23.0 (IBM Co., Armonk, NY, USA).

\section{RESULTS}

\section{Demographic characteristics}

Table 1 shows the results of the frequency analysis on the general characteristics of the subjects for each major demographic variable. There were 1,891 males (84.2\%) and 354 females (15.8\%). A total of 446 people $(19.9 \%)$ were in their $40 \mathrm{~s}$, the largest percentage, and 81 patients $(3.6 \%)$ were older than age, the smallest percentage. The frequency of income level was highest at 635 people (28.3\%) in the upper-middle level, and lowest at 400 people $(17.8 \%)$ in the lower level. The frequency of education level was highest at 866 people (38.6\%) in the university education level. In this study, 1,687 people (74.7\%) were married and 1,573 people $(70.1 \%)$ were employed.

Based on drinking more than one glass per month in the last year, there were 1,632 (72.7\%) responded that they drank alcohol. Additionally, 899 people $(40.0 \%)$ responded that they smoked daily, 153 people $(6.8 \%)$ responded that they smoked occasionally, and 1,193 people (53.1\%) responded that they did not ever smoke.

In the BMI, normal comprised 878 (47.9\%), and obesity comprised 88 (4.4\%). Looking at the aerobic 
Table 1. Demographic characteristics of the subjects

\begin{tabular}{|c|c|c|c|c|}
\hline Variable & Frequency & $\%$ & Mean & SD \\
\hline \multicolumn{5}{|l|}{ Sex } \\
\hline Male & 1,891 & 84.2 & & \\
\hline Female & 354 & 15.8 & & \\
\hline Age & & & 50.73 & 16.20 \\
\hline 30 s under & 229 & 10.2 & & \\
\hline $30 \mathrm{~s}$ & 435 & 19.4 & & \\
\hline $40 \mathrm{~s}$ & 446 & 19.9 & & \\
\hline $50 \mathrm{~s}$ & 412 & 18.4 & & \\
\hline $60 \mathrm{~s}$ & 368 & 16.4 & & \\
\hline $70 s$ & 274 & 12.2 & & \\
\hline 80 s more than & 81 & 3.6 & & \\
\hline \multicolumn{5}{|l|}{ Income } \\
\hline Low & 400 & 17.8 & & \\
\hline Medium & 581 & 25.9 & & \\
\hline Moderate & 635 & 28.3 & & \\
\hline High & 629 & 28.0 & & \\
\hline \multicolumn{5}{|l|}{ Education } \\
\hline Elementary & 363 & 16.2 & & \\
\hline Middle & 255 & 11.4 & & \\
\hline High & 761 & 33.9 & & \\
\hline University & 866 & 38.6 & & \\
\hline \multicolumn{5}{|l|}{ Marital status } \\
\hline Married & 1,678 & 74.7 & & \\
\hline Single & 567 & 25.3 & & \\
\hline \multicolumn{5}{|l|}{ Job status } \\
\hline Occupation & 1,573 & 70.1 & & \\
\hline Inoccupation & 672 & 29.9 & & \\
\hline \multicolumn{5}{|l|}{ Alcohol drinking } \\
\hline Non-drinker & 613 & 27.3 & & \\
\hline Drinker & 1,632 & 72.7 & & \\
\hline \multicolumn{5}{|l|}{ Current smoking } \\
\hline Everyday & 899 & 40.0 & & \\
\hline Sometimes & 153 & 6.8 & & \\
\hline None & 1,193 & 53.1 & & \\
\hline $\mathrm{BMI}$ & & & 24.37 & 3.48 \\
\hline Low weight $(<20)$ & 112 & 6.1 & & \\
\hline Normal $(20 \leq,<25)$ & 878 & 47.9 & & \\
\hline Mild obesity $(25 \leq,<30)$ & 754 & 41.2 & & \\
\hline Obesity $(\geq 30)$ & 88 & 4.8 & & \\
\hline \multicolumn{5}{|l|}{ Aerobic physical activity } \\
\hline No & 1,235 & 55.0 & & \\
\hline Yes & 1,010 & 45.0 & & \\
\hline
\end{tabular}

$\mathrm{SD}$, standard deviation; BMI, body mass index.

exercise rate, 1,235 people (55.0\%) responded 'No' and 1,010 people (45.0\%) were 'Yes', with more non-aerobic groups.

\section{Physical activity and $P H Q-9$ score}

Descriptive statistical analysis was performed to de- 
termine the descriptive statistics of physical activity variables and PHQ-9 scores. The results are shown in Table 2. The first DDWE was 4.67 days, and the TTWWE was 0.76 hours. The DWMSE was 1.87 days and the mean score of PHQ-9 was 2.72 .

\section{Comparative analysis of $\mathrm{PHQ}-9$ scores according to sex, marital status, current job status, and drinking status (one glass or more monthly for the last year)}

Table 3 shows the difference in physical activity and PHQ-9 scores according to sex. And, it also shows the differences in PHQ-9 scores according to marital status, occupational status, and drinking status using the t-test.

The differences in physical activity according to sex showed that DDWE, TTWWE, and DWMSE were higher for males than for females. In contrast, the mean

Table 2. Descriptive statistical analysis of major variables

\begin{tabular}{lcllc}
\hline \multicolumn{1}{c}{ Variable } & Number & Range & Mean & SD \\
\hline DWWE (d) & 2,245 & $0-7$ & 4.67 & 2.677 \\
TTWWE (h) & 1,782 & $0-10$ & 0.76 & 1.178 \\
DWMSE (d) & 2,245 & $0-6$ & 1.87 & 1.629 \\
PHQ-9 score & 2,245 & $0-27$ & 2.72 & 3.953 \\
\hline
\end{tabular}

SD, standard deviation; DWWE, the days of weekly walking exercise; TTWWE, total time of weekly walking exercise; DWMSE, the days of weekly muscle-strengthening exercise; $\mathrm{PHQ}-9$, Patient Health Questionnaire-9. scores of PHQ-9 were lower for males than for females (2.22 vs. 5.35). The mean PHQ-9 scores according to the current marital status was higher in those who were married than those who were not married. For the PHQ9 scores based on current job status, the mean PHA- 9 score was higher if there were unemployed. Conversely, the group who drank more than one drink monthly in the last year had a lower PHQ-9 mean score than the group who did not drink. All results are statistically significant differences.

\section{Differences in PHQ-9 scores by age, income, education, current smoking status and BMI}

Table 4 shows the differences in PHQ-9 scores according to age, income level, final education, current smoking status, and BMI. The differences in PHQ-9 scores by age, income level, educational attainment, and smoking were all statistically significant, except by BMI. In terms of age, the mean PHQ-9 score for those younger than age 30 was the highest with 3.58 , and the average score for those in their $60 \mathrm{~s}$ was the lowest with 2.28 .

In the case of income levels, the lower the income level, the higher the PHQ-9 scores. For education, the mean PHQ-9 scores in the group below elementary school (3.36) was the highest. The higher the education level, the lower the average PHQ-9 scores. The mean PHQ9 scores according to smoking status were lower in the non-smoking group, and the difference in PHQ-9 scores by BMI was not statistically significant, but the average

Table 3. Differences in physical activity by sex and PHQ-9 scores by sex, marriage status, job status and alcohol drinking

\begin{tabular}{|c|c|c|c|c|c|c|}
\hline \multirow{2}{*}{ Variable } & \multicolumn{2}{|c|}{ Male } & \multicolumn{2}{|c|}{ Female } & \multirow{2}{*}{$\mathrm{t}$} & \multirow{2}{*}{$p$-value } \\
\hline & Mean & SD & Mean & SD & & \\
\hline DWWE (d) & 4.72 & 2.688 & 4.41 & 2.610 & 2.000 & $0.046 *$ \\
\hline TTWWE (h) & 0.77 & 1.178 & 0.70 & 1.173 & 0.936 & 0.349 \\
\hline DWMSE (d) & 1.95 & 1.688 & 1.44 & 1.182 & 5.507 & $<0.001 * \star$ \\
\hline PHQ-9 score & 2.22 & 3.411 & 5.35 & 5.365 & 14.259 & $<0.001 * \star$ \\
\hline \multirow[t]{6}{*}{ PHQ-9 score } & \multicolumn{2}{|c|}{ Married } & \multicolumn{2}{|c|}{ Single } & & \\
\hline & 2.28 & 3.480 & 4.02 & 4.881 & -9.232 & $<0.001 \star \star$ \\
\hline & \multicolumn{2}{|c|}{ Occupation } & \multicolumn{2}{|c|}{ Inoccupation } & & \\
\hline & 2.30 & 3.301 & 3.69 & 5.037 & -7.764 & $<0.001 * \star$ \\
\hline & \multicolumn{2}{|c|}{ Non-drinker } & \multicolumn{2}{|c|}{ Drinker } & & \\
\hline & 3.09 & 4.357 & 2.58 & 3.782 & 2.768 & $0.006 * *$ \\
\hline
\end{tabular}

PHQ-9, Patient Health Questionnaire-9; SD, standard deviation; DWWE, the days of weekly walking exercise; TTWWE, total time of weekly walking exercise; DWMSE, the days of weekly muscle-strengthening exercise.

$\star p<0.05, * \star p<0.01$. 
Seo Hee Park, et al. Physical Activities Helping You Feel Better

Table 4. Differences in $\mathrm{PHQ}-9$ scores by age, income, education, and current smoking

\begin{tabular}{|c|c|c|c|c|c|}
\hline \multirow{2}{*}{ Variable } & \multicolumn{2}{|c|}{ PHQ-9 Score } & \multirow{2}{*}{$\mathrm{F}$} & \multirow{2}{*}{$p$-value } & \multirow{2}{*}{ Scheffe } \\
\hline & Mean & SD & & & \\
\hline Age & & & 5.614 & $<0.001 \star \star$ & \\
\hline 30s under & 3.58 & 4.168 & & & \\
\hline $30 s$ & 3.35 & 4.195 & & & \\
\hline $40 \mathrm{~s}$ & 2.37 & 3.465 & & & \\
\hline $50 \mathrm{~s}$ & 2.38 & 3.745 & & & \\
\hline $60 \mathrm{~s}$ & 2.28 & 4.129 & & & \\
\hline $70 s$ & 2.62 & 3.923 & & & \\
\hline 80 s more than & 2.83 & 4.165 & & & \\
\hline Total & 2.72 & 3.953 & & & \\
\hline Income & & & 19.313 & $<0.001 * \star$ & \\
\hline Low & 3.78 & 5.161 & & & \\
\hline Medium & 3.09 & 4.252 & & & \\
\hline Moderate & 2.33 & 3.410 & & & \\
\hline High & 2.09 & 3.014 & & & \\
\hline Total & 2.72 & 3.953 & & & \\
\hline Education & & & 6.531 & $<0.001 * \star$ & \\
\hline Elementary & 3.36 & 4.896 & & & \\
\hline Middle & 2.75 & 4.299 & & & \\
\hline High & 2.85 & 3.980 & & & \\
\hline University & 2.32 & 3.290 & & & \\
\hline Total & 2.72 & 3.953 & & & \\
\hline Current smoking & & & 14.678 & $<0.001 \star \star$ & \\
\hline Everyday & 3.18 & 4.454 & & & \\
\hline Sometimes & 3.25 & 4.175 & & & \\
\hline None & 2.30 & 3.446 & & & \\
\hline Total & 2.72 & 3.953 & & & \\
\hline $\mathrm{BMI}$ & & & 2.557 & 0.054 & $\mathrm{n} / \mathrm{a}$ \\
\hline Low weight $(<20)$ & 3.55 & 4.360 & & & \\
\hline Normal $(20 \leq,<25)$ & 2.83 & 4.213 & & & \\
\hline Mild obesity $(25 \leq,<30)$ & 2.55 & 3.665 & & & \\
\hline Obesity $(\geq 30)$ & 3.17 & 4.437 & & & \\
\hline Total & 2.77 & 4.023 & & & \\
\hline
\end{tabular}

PHQ-9, Patient Health Questionnaire-9; SD, standard deviation; BMI, body mass index; n/a, not available. $\star \star p<0.01$.

Table 5. Correlation between variables

\begin{tabular}{|c|c|c|c|c|c|}
\hline Variable & DWWE & TTWWE & DWMSE & RAPAES & PHQ-9 score \\
\hline DWWE (d) & 1 & & & & \\
\hline TTWWE (h) & $0.140 \star \star$ & 1 & & & \\
\hline DWMSE (d) & $0.228 * \star$ & 0.046 & 1 & & \\
\hline RAPAES & $0.379 \star \star$ & $0.110 * \star$ & $0.212 \star \star$ & 1 & \\
\hline PHQ-9 score & $-0.073 \star \star$ & 0.005 & $-0.094 \star \star$ & $-0.045 \star$ & 1 \\
\hline
\end{tabular}

DWWE, the days of weekly walking exercise; TTWWE, total time of weekly walking exercise; DWMSE, the days of weekly musclestrengthening exercise; RAPAES, recommended aerobic physical activity execution status; PHQ-9, Patient Health Questionnaire-9. $\star p<0.05, * \star p<0.01$. 
PHQ-9 scores tended to be higher in the underweight and obesity groups compared to the normal and mild obesity groups.

\section{Correlation between physical activities and PHQ-9 scores}

Pearson's correlation analysis was used to observe the correlation between physical activities and the mean PHQ-9 scores and the results are shown in Table 5. DWWE, DWMSE and RAPAES are a statistically significant correlation with the PHQ-9 Scores. The correlation coefficients with PHQ-9 scores were -0.073 for DWWE (unit: days), -0.094 for DWMSE, and -0.045 for RAPAES. DWNSE and PHQ-9 scores have the largest negative correlation.

Table 6. Hierarchical regression analysis results of variables influencing PHQ-9 score

(A)

\begin{tabular}{|c|c|c|c|c|c|c|c|c|c|c|}
\hline \multirow[t]{2}{*}{ M } & \multirow{2}{*}{\multicolumn{2}{|c|}{ Dependent variable }} & \multicolumn{2}{|c|}{$\begin{array}{l}\text { Unstandardized } \\
\text { coefficients }\end{array}$} & \multirow{2}{*}{$\begin{array}{c}\begin{array}{c}\text { Stand } \\
\text { coefficients }\end{array} \\
\text { Beta }\end{array}$} & \multirow[t]{2}{*}{$\mathrm{t}$} & \multirow[t]{2}{*}{ Sig. } & \multicolumn{2}{|c|}{ Collinearity statistics } & \multirow[t]{2}{*}{$\mathrm{F}$} \\
\hline & & & B & SE & & & & Tolerance & VIF & \\
\hline \multirow[t]{11}{*}{1} & (Constant) & & 8.009 & 0.832 & & 9.627 & 0.000 & & & $27.965 * \star(<0.001)$ \\
\hline & Sex & & -2.399 & 0.253 & -0.227 & -9.470 & $0.000 * \star$ & 0.849 & 1.178 & \\
\hline & Age & & -0.015 & 0.007 & -0.062 & -1.995 & 0.046 & 0.506 & 1.976 & \\
\hline & Income & & -0.407 & 0.092 & -0.113 & -4.416 & $0.000 *$ & 0.740 & 1.352 & \\
\hline & Education & & -0.102 & 0.104 & -0.028 & -0.982 & 0.326 & 0.614 & 1.629 & \\
\hline & Marriage & & -0.921 & 0.217 & -0.106 & -4.237 & $0.000 \star \star$ & 0.779 & 1.284 & \\
\hline & Occupation & & -0.647 & 0.204 & -0.078 & -3.169 & $0.002 \star \star$ & 0.811 & 1.233 & \\
\hline & Alcohol drinking & & -0.194 & 0.202 & -0.022 & -0.960 & 0.337 & 0.922 & 1.085 & \\
\hline & Everyday smoking & & 0.759 & 0.186 & 0.097 & 4.080 & $0.000 * \star$ & 0.859 & 1.165 & \\
\hline & Sometimes smokin & & 0.560 & 0.340 & 0.038 & 1.649 & 0.099 & 0.897 & 1.115 & \\
\hline & BMI & & -0.011 & 0.024 & -0.010 & -0.467 & 0.640 & 0.972 & 1.028 & \\
\hline \multirow[t]{15}{*}{2} & (Constant) & & 8.636 & 0.862 & & 10.024 & 0.000 & & & \\
\hline & Sex & & -2.331 & 0.255 & -0.221 & 9.158 & $0.000 * \star$ & 0.837 & 1.194 & \\
\hline & Age & & -0.013 & 0.007 & -0.057 & 1.820 & 0.069 & 0.501 & 1.996 & \\
\hline & Income & & -0.397 & 0.092 & -0.111 & -4.309 & $0.000 * \star$ & 0.737 & 1.357 & \\
\hline & Education & & -0.091 & 0.104 & -0.025 & -0.871 & 0.384 & 0.609 & 1.643 & \\
\hline & Marriage & & -1.004 & 0.219 & -0.116 & 4.591 & $0.000 * \star$ & 0.765 & 1.307 & \\
\hline & Occupation & & -0.684 & 0.205 & -0.082 & 3.344 & $0.001 \star \star$ & 0.806 & 1.241 & \\
\hline & Alcohol drinking & & -0.170 & 0.202 & -0.019 & -0.840 & 0.401 & 0.918 & 1.089 & \\
\hline & Everyday smoking & & 0.720 & 0.186 & 0.092 & 3.863 & $0.000 * \star$ & 0.851 & 1.175 & $20.845 \star \star(<0.001)$ \\
\hline & Sometimes smokin & & 0.541 & 0.339 & 0.037 & 1.596 & 0.111 & 0.895 & 1.117 & \\
\hline & $\mathrm{BMI}$ & & -0.016 & 0.024 & -0.014 & -0.646 & 0.518 & 0.968 & 1.033 & \\
\hline & DWWE & & -0.102 & 0.042 & -0.057 & -2.416 & $0.016 \star$ & 0.858 & 1.165 & \\
\hline & TTWWE & & 0.095 & 0.072 & 0.030 & 1.316 & 0.188 & 0.964 & 1.037 & \\
\hline & DWMSE & & -0.090 & 0.051 & -0.040 & -1.763 & 0.078 & 0.921 & 1.085 & \\
\hline & RAPAES & & 0.124 & 0.182 & 0.016 & 0.680 & 0.496 & 0.849 & 1.179 & \\
\hline \multicolumn{11}{|l|}{ (B) } \\
\hline M & $\mathrm{R}$ & $\mathrm{R}^{2}$ & \multicolumn{2}{|c|}{$\begin{array}{l}\text { Adjusted } \\
\text { R square }\end{array}$} & $\begin{array}{l}\text { SE of the } \\
\text { estimate }\end{array}$ & $\begin{array}{l}\text { R Square } \\
\text { change }\end{array}$ & \multicolumn{2}{|c|}{ F change } & Sig. F change & Durbin-watson \\
\hline 1 & 0.369 & 0.136 & \multicolumn{2}{|c|}{0.131} & 3.544 & 0.136 & \multicolumn{2}{|c|}{27.965} & 0.000 & 1.973 \\
\hline 2 & 0.376 & 0.142 & \multicolumn{2}{|c|}{0.135} & 3.537 & 0.005 & \multicolumn{2}{|c|}{2.767} & 0.026 & \\
\hline
\end{tabular}

PHQ-9, Patient Health Questionnaire-9; M, model; SE, standard error; Sig., significance; VIF, variation inflation factor; BMI, body mass index; DWWE, the days of weekly walking exercise; TTWWE, total time of weekly walking exercise; DWMSE, the days of weekly musclestrengthening exercise; RAPAES, recommended aerobic physical activity execution status. 


\section{Hierarchical regression analysis results of variables influencing PHQ-9 score (hierarchical regression results)}

The results are shown in Table 6. The independent variables were DWWE, TTWWE, DWNSE, PARAES, and the dependent variable was the total score of PHQ-9. Covariates included sex, age, income, education, marital status, job status, drinking, smoking status, and BMI. The final model's F-value was 20.845 and the regression model was statistically significant.

The $\mathrm{R}^{2}$ was $14.2 \%$ and it is the same as the coefficient of determination, which is the percentage of total variation in the dependent variable that can be explained by the variable factor. When the confounding variables were corrected, DWSME, TTWWE and RAPAES did not have a statistically significant effect on the PHQ-9 scores. Conversely, DWWE was the only physical activity variable that had a statistically significant negative effect even when the confounding variable was controlled. That is, since the value of the non-standardized beta (B) was -0.102 , the PHQ-9 scores decreased by -0.102 as DWWE increased during the week.

\section{DISCUSSION}

This study used data of adults older than age 19 from the 2016 KNHANES. The purpose of this study was to examine the association between DWWE, TTWWE, DWMSE, RAPAES, and the degree of depression measured by PHQ-9.

As a result, when the demographic and clinical characteristics were corrected, the more days people walked weekly, the lower their total score on PHQ-9. This result is consistent with the results of previous studies on the association between walking and depressive symptom. Walking exercise has been shown to both reduce depressive symptoms and prevent depression. In study of the preventive effect, regular walking among middleage females, conducted more than three times weekly, had a positive effect on stress perception and depression [20]. Walking can be performed without limitations of equipment, places, and facilities, and it is an easy and effective exercise for reducing stress [25], increasing energy consumption and the fat oxidation rate, and improving muscle mobilization. Thus, it prevents obesity and chronic diseases [26]. And, Katon [27] reported that chronically ill patients had a higher prevalence of major depression than the general population because of decreased physical activity.

In addition, studies showing that walking helps to alleviate depressive symptoms include studies showing depression on older people, 13 weeks of walking exercise [28] and 12 weeks of Nordic walking [29]. Recently, many studies have been conducted to investigate the relationship between depression, obesity, aging, immune response, and stress hormones. Depressed females age 18-20 were instructed to run five times weekly. After eight weeks, their degree of depression was reduced, as well as the stress hormones such as cortisol, epinephrine [9], and ACTH levels [30]. Additionally, increased high-sensitivity $\mathrm{C}$-reactive protein and the development of insulin-resistant Type 1 diabetes, associated with depression, were prevented with regular aerobic exercise $[8,31,32]$. Thus, walking to improve depression alleviates the symptoms of depression, as well as improves the risk factors of chronic diseases affecting depression, so the effect of depression treatment is expected to be considerable. Another interesting result of this study was that the correlation with PHQ-9 score was greater in DWNSE than DWWE before the covariate was corrected. However, after adjusting for the covariates, DWMSE was not correlated with PHQ-9.

The relationship between DWMSE and depression can be explained by a report that muscle-strengthening is more likely to be beneficial for depression than daily physical activity or flexibility exercise [33]. And this can be explained by the study that lowering muscle mass and strength are risk factors for depression [34]. But there was no independent correlation of DWMSE with PHQ-9 when the covariates were corrected in our study.

It may be speculated that the decrease in muscle mass does not affect depression directly, but leads to decrease in physical activities such as aerobic exercise and finally leads to depression [19]. Previous studies have recommended muscle-strengthening for improving depression, but this supports the fact that it works only in conjunction with aerobic exercise [33].

Meanwhile, when the covariates were corrected, there was a significant correlation between depression and walking days rather than the duration of walking. This result may be evidence for suggesting specific and feasible ways of physical exercise for preventing depression.

This study has limitations. First, this study is a crosssectional study. It can reveal the association between 
physical activities and depression, but not a causal relationship. Thus, follow-up studies such as a time series analysis to identify causality between physical activities and depression should be conducted in the future. Second, the KNHANES data are not a survey conducted for professional psychiatric evaluations and the assessment of depression depends on the PHQ-9 self-report scale, indicating that the accuracy of the depression assessment is low. So, further research is needed by using the latest advanced information communication technology and physical activity measurement method.

However, this study has some significant advantages. First, we applied reliable data that can represent the entire population of Korea by reflecting weights in the 2016 KNHANES data, led by the state. Second, the size of the sample is large, and it has strength in that several moderator variables can be used. Third, unlike previous studies, we compared walking and muscle strengthening, and suggested a specific method of walking that is more related to depression. Even walking had a positive effect on depression. Its antidepressant effect works when walking is regular and consistent, but it is not crucial to walk for a lengthy time.

Based on the results of this study, studies on the causal relationship between physical activities and depression, as well as studies on the association of physical activities with other mental health problems are needed. If such research is undertaken, the impact of walking on mental health could be further elucidated. And then, this will significantly facilitate improving the quality of life for people globally.

\section{CONCLUSION}

In this study, the more weekly walking was in the Korean general population, the lower the score of the depression scale, PHQ-9. This supports the fact that walking and symptoms of depression are related. Also, when the variables were corrected, PHQ-9 had a significant correlation with the number of days of walking exercise rather than the duration of walking exercise. And, the number of days for muscle-strengthening exercise for one week were not significant. In other words, for adults older than age 19, aerobic physical activity such as walking exercise especially not by duration but by regular and steady engagement had more impact on depressive symptoms than muscle strengthening. Based on these results, it may be beneficial to suggest the appropriate direction to practice regarding physical activity to facilitate the improvement of mood.

\section{CONFLICTS OF INTEREST}

The authors have nothing to disclose.

\section{ORCID}

\author{
Seo Hee Park \\ https://orcid.org/0000-0001-5657-428X \\ Young Myo Jae \\ https://orcid.org/0000-0003-4557-0827 \\ Sae Heon Jang \\ https://orcid.org/0000-0002-4186-1101 \\ Jin-Hyuk Choi \\ https://orcid.org/0000-0003-0892-9335 \\ Gyeong Hwan Lee \\ https://orcid.org/0000-0002-7246-1653
}

\section{REFERENCES}

1. Lovibond PF, Lovibond SH. The structure of negative emotional states: comparison of the Depression Anxiety Stress Scales (DASS) with the Beck Depression and Anxiety Inventories. Behav Res Ther 1995;33:335-43.

2. World Health Organization. Depression [Internet]. Geneva: World Health Organization; 2018 [cited 2020 Jan 30]. Available from: https://www.who.int/news-room/factsheets/detail/depression.

3. Statistics Korea. 2017 Cause of death statistics [Internet]. Daejeon: Statistics Korea; 2017 [cited 2018 Sep 19]. Available from: http://kostat.go.kr/portal/korea/kor_nw/1/6/2/ index.board? bmode $=$ read $\& b S e q=\& a S e q=370710 \&$ pageNo $=1$ \&rowNum $=10 \&$ navCount $=10 \&$ currPg $=\&$ searchInfo $=\& \mathrm{~s}$ Target $=$ title\&sTxt $=$.

4. Lee YM, Park HS. A study on the stage of change in exercise behaviors, exercise self efficacy, depression and stress in middle aged women. Korean J Women Health Nurs 2004;10:218-25.

5. Gill DL, Chang YK, Murphy KM, Speed KM, Hammond CC, Rodriguez EA, et al. Quality of life assessment for physical activity and health promotion. Appl Res Qual Life 2011;6:181-200.

6. Trost SG, Pate RR, Dowda M, Saunders R, Ward DS, Felton G. Gender differences in physical activity and determinants of physical activity in rural fifth grade children. J Sch 
Health 1996;66:145-50

7. Sallis JF, Hovell MF, Hofstetter CR. Predictors of adoption and maintenance of vigorous physical activity in men and women. Prev Med 1992;21:237-51.

8. Corbin CB, Welk G, Corbin WR, Welk K. Concepts of fitness and wellness: a comprehensive lifestyle approach. 6th ed. New York: McGraw-Hill; 2006. p. 6.

9. Nabkasorn C, Miyai N, Sootmongkol A, Junprasert S, Yamamoto H, Arita M, et al. Effects of physical exercise on depression, neuroendocrine stress hormones and physiological fitness in adolescent females with depressive symptoms. Eur J Public Health 2005;16:179-84.

10. Kim NJ, Suh I. The relationship between exercise and perceived stress in employees. Korean J Health Educ Promot 2004;21:101-15.

11. Kim YS, Lee Y, Chung YS, Lee DJ, Joo NS, Hong D, et al. Prevalence of sarcopenia and sarcopenic obesity in the Korean population based on the Fourth Korean National Health and Nutritional Examination Surveys. J Gerontol A Biol Sci Med Sci 2012;67:1107-13.

12. World Health Organization. Physical activity [Internet]. Geneva: World Health Organization; 2018 [cited 2018 Feb 23]. Available from: https://www.who.int/news-room/factsheets/detail/physical-activity.

13. U.S. Department of Health and Human Services. 2008 Physical activity guidelines for Americans [Internet]. Office of Disease Prevention and Health Promotion; 2008 [cited 2008 Feb 11]. Available from: https://health.gov/paguidelines/guidelines/chapter3.aspx.

14. Australian Government Department of Health. Australia's physical activity and sedentary behaviour guidelines and the Australian 24-hour movement guidelines. Australian Government Department of Health; 2017 [cited 2017 May 23]. Available from: http://www.health.gov.au/internet/ main/publishing.nsf/content/health-pubhlth-strateg-physact-guidelines\#apa512.

15. Tremblay MS, Warburton DE, Janssen I, Paterson DH, Latimer AE, Rhodes RE, et al. New Canadian physical activity guidelines. Appl Physiol Nutr Metab 2011;36:36-46; 47-58.

16. Korea Ministry of Health and Welfare. The physical activity guid for Koreans. Korea Ministry of Health and Welfare; 2013.

17. Kim SY. PUBLIC HEALTH WEEKLY REPORT, KCDC. Adults physical activity in Korea [Internet]. Korea Centers for Disease Control \& Prevention (KCDC): 2014 [cited 2014 Jan 31]. Available from: http://www.cdc.go.kr/board. es? $\mathrm{mid}=\mathrm{a} 20602010000 \& \mathrm{bid}=0034 \& \mathrm{tag}=\&$ act $=$ view\&list no $=24149$

18. Early Release of Selected Estimates Based on Data From the January-June 2013 National Health Interview Survey [Internet]. Centers for Disease Control \& Prevention (CDC): 2013 [cited 2013 Dec 17]. Available from: https://www.cdc. gov/nchs/data/nhis/earlyrelease/earlyrelease201312_13.pdf
19. Kwon HJ, Kim HJ. Association between muscle mass and depression in Korean elderly women. Korea Soc Well 2015;10:283-91.

20. Kang IW, Cho WJ. The influence on mental health status and health-related quality of life in middle-aged women by the regular walking exercise: by based on the Korea National Health and Nutrition Examination Survey (KNHANES VI). Korea Soc Well 2016;11:207-15.

21. McNeil JK, LeBlanc EM, Joyner M. The effect of exercise on depressive symptoms in the moderately depressed elderly. Psychol Aging 1991;6:487-8.

22. Meyer T, Broocks A. Therapeutic impact of exercise on psychiatric diseases: guidelines for exercise testing and prescription. Sports Med 2000;30:269-79.

23. Kim SR, Shin HC, Lee DC, Kim CH, Sung EJ, Lee KH, et al. Use of the PHQ-2/PHQ-9 serial screening instrument for detecting major depressive disorder in primary care. Korean J Stress Res 2011;19:405-10.

24. An JY, Seo ER, Lim KH, Shin JH, Kim JB. Standardization of the Korean version of screening tool for depression (Patient Health Questionnaire-9, PHQ-9). J Korean Soc Biol Ther Psychiatr 2013;19:47-56.

25. Jang YH, Kim SH, Kim YS, Jung SH, Park J. The relationship between walking exercise and quality of life for Korean adults. J Digit Converg 2013;11:325-34.

26. Horowitz JF. Fatty acid mobilization from adipose tissue during exercise. Trends Endocrinol Metab 2003;14:386-92.

27. Katon WJ. Clinical and health services relationships between major depression, depressive symptoms, and general medical illness. Biol Psychiatry 2003;54:216-26.

28. Huh YG, Jung WS, Lee MG. Effects of a 13-week outdoor group walking exercise on depression and its' related variables in elderly women. Korea J Sports Sci 2014;23:135164.

29. Lee HS, Park JH. Effects of Nordic walking on physical functions and depression in frail people aged 70 years and above. J Phys Ther Sci 2015;27:2453-6.

30. Noh KS. The effects of walking exercise on ACTH, cortisol and $\beta$-endorphin. Korea Med Sports 1998;16:233-7.

31. Lakier Smith L. Overtraining, excessive exercise, and altered immunity: is this a T helper-1 versus T helper-2 lymphocyte response? Sports Med 2003;33:347-64.

32. Lyoo IK, Yoon S, Jacobson AM, Hwang J, Musen G, Kim JE, et al. Prefrontal cortical deficits in type 1 diabetes mellitus: brain correlates of comorbid depression. Arch Gen Psychiatry 2012;69:1267-76.

33. Park SY. Associations with physical activity, chronic disease, depression, and health-related quality of life. Korean J Sport Sci 2014;25:249-58.

34. Kim JH, Hwang BY, Hong ES, Ohn JH, Kim CH, Kim HW, et al. Investigation of sarcopenia and its association with cardiometabolic risk factors in elderly subjects. J Korean Geriatr Soc 2010;14:121-30. 